\title{
REESCRITURAÇÕES DO SENTIDO DE LÍNGUA NO IMAGINÁRIO DO SENSO COMUM: O FUNCIONAMENTO SEMÂNTICO DO (RE)DIZER ${ }^{1}$
}

\section{REWRITING OF THE SENSE OF LANGUAGE IN THE COMMON SENSE IMAGERY: THE SEMANTIC FUNCTIONING OF (RE)SAYING}

\author{
Rejane Fiepke Carpenedo* \\ UFSM \\ Eliana Rosa Sturza** \\ UFSM
}

Resumo: Este artigo é parte de uma pesquisa de Mestrado que teve como objetivo compreender os sentidos de língua no imaginário do senso comum, na perspectiva linguística da semântica enunciativa. Propõe-se a analisar como se dá o funcionamento semântico do (re)dizer no processo analítico de reescrituração. O aporte teórico-metodológico dá-se a partir da Teoria da Enunciação, pelo viés da Semântica do Acontecimento (GUIMARÃES, 2002b). Dessa forma, com os operadores enunciativos da reescrituração referidos, analisam-se os sentidos de língua presentes no imaginário do senso comum, e, posteriormente, a recorrência dos modos de reescrituração e seu funcionamento semântico. Observou-se que os modos de substituição e repetição são os mais usados, movimentando sentidos de especificação, sinonímia e definição. Os modos e os sentidos de reescrituração permitem inferir sobre o quanto ainda se confunde, no discurso do senso comum, o uso escrito e falado da língua, em que se atribui a correção e a norma à modalidade oral. Assim, surge um conflito entre o funcionamento linguístico e o funcionamento enunciativo, em que o "bem falar" é idealizado e funciona como critério que qualifica, ou não, o sujeito para ocupar os espaços sociais de poder e visibilidade, bem como os enunciados apresentam o ponto de vista de uma língua imaginária.

Palavras-chave: Enunciação. Sentido de língua. Reescrituração.

\footnotetext{
${ }^{1}$ Este artigo é parte de nossa dissertação de Mestrado intitulada A reescrituração e os sentidos de língua na perspectiva do senso comum: ideologia e imaginário (CARPENEDO, 2017), vinculada ao Mestrado em Letras/Estudos Linguísticos do Programa de Pós-Graduação da Universidade Federal de Santa Maria (UFSM), orientada pela Professora Doutora Eliana Rosa Sturza. Em nossa pesquisa, buscamos compreender quais são os sentidos de Língua no senso comum, a partir da análise de comentários de internautas na rede social Facebook. Para este artigo, apresentamos um pequeno recorde que consiste na análise de quatro Sequências Enunciativas mobilizadas na dissertação. Este trabalho foi realizado com apoio da Coordenação de Aperfeiçoamento de Pessoal de Nível Superior - Brasil (CAPES) - Código de Financiamento 001

* Doutoranda em Letras/Estudos Linguísticos pelo Programa de Pós-Graduação em Letras da Universidade Federal de Santa Maria (UFSM) e Bolsista da CAPES. Mestra em Letras/Estudos Linguísticos pelo Programa de Pós-Graduação em Letras da UFSM. Bacharela em Jornalismo pela UFSM. ORCID: https://orcid.org/0000-0001-7151-666X. E-mail: rejanefiepke@hotmail.com.

** Professora Associada da Universidade Federal de Santa Maria (UFSM), do Departamento de Letras Estrangeiras Modernas. Coordenadora do Programa de Pós-Graduação em Letras da UFSM e Coordenadora do Núcleo Disciplinar de Ensino de Português e Espanhol como Línguas Segundas e Estrangeiras, da Associação das Universidades do Grupo de Montevidéu. Possui Doutorado em Linguística pela Universidade Estadual de Campinas (2006), Mestrado em Educação pela UFSM (1994), e Graduação em Letras pela UFSM (1988). ORCID: https://orcid.org/0000-0003-4085-0096. E-mail: listurza@gmail.com.
} 


\begin{abstract}
This article is part of a Master's thesis research that aimed to understand the meanings of language in the imagery of common sense, in the linguistic perspective of enunciative semantics. The proposal is to analyze how the semantic functioning of (re)saying occurs in the analytical process of rewriting. The theoretical-methodological support is based on the Theory of Enunciation, in the perspective of the Semantics of the Event (GUIMARÃES, 2002b). In this way, with the enunciative operators of rewriting mentioned, the meanings of language present in the imagery of common sense are analyzed, and subsequently the recurrence of modes of rewriting and its semantic functioning. It was observed that the substitution and repetition modes are the most used, moving directions of specification, synonym and definition. The ways and meanings of rewriting allow to infer about how much the written and spoken use of language is still confused in the discourse of common sense, in which correction and the norm are attributed to the oral modality. Thus, a conflict arises between the linguistic function and the enunciative function, in which "good speech" is idealized and works as a criterion that qualifies, or not, the subject to occupy the social spaces of power and visibility, and the statements present the point of view of an imaginary language.
\end{abstract}

Keywords: Enunciation. Sense of language. Rewriting.

\title{
INTRODUÇÃO
}

Neste artigo, buscamos compreender os sentidos de língua na perspectiva do senso comum, por meio do funcionamento da reescrituração dos enunciados. Para tal, adotamos como aporte teórico-metodológico a Teoria da Enunciação, com ênfase na Semântica do Acontecimento segundo os pressupostos de Guimarães (2002b).

A reflexão suscitada aqui consiste no recorte de uma das perspectivas abordadas em nossa dissertação de Mestrado, intitulada A reescrituração e os sentidos de língua na perspectiva do senso comum: ideologia e imaginário (CARPENEDO, 2017) dá-se a partir de enunciados de internautas (locutores) referentes à língua portuguesa, compreendidos como os dizeres do senso comum sobre a língua. Tradicionalmente, as pesquisas no âmbito da linguística voltadas aos discursos sobre a língua detêm-se nos discursos de gramáticos, escritores e instituições, e raras vezes lança-se um olhar para essa questão a partir da perspectiva do imaginário do senso comum.

Assim, defrontamo-nos com novos movimentos de sentidos, oriundos de direções ainda pouco investigadas - o senso comum. Há, nessa esfera, um imaginário amplamente disseminado sobre língua, o de que a língua é homogênea, e apenas uma forma pode ser considerada como correta. Em relação a isso, Dias (2018) afirma que:

No que diz respeito à intolerância linguística produzida entre essa "nova classe trabalhadora” em ascendência e a classe média conservadora é uma disputa no campo da língua, que metaforiza uma disputa política, ética e cognitiva. E podemos dizer que essa divisão se reflete no espaço da língua, há uma língua de "elite” e uma língua do povo. A língua é também, portanto, fator de desigualdade, divisão, poder. (DIAS, 2018, p. 172).

Além disso, estamos mediante o desafio de pensar a enunciação a partir de outro viés, outra materialidade, outro espaço político de funcionamento - o digital. Dias (2018, p. 170) empreendeu um estudo na perspectiva da Análise de Discurso Francesa sobre o discurso digital, e, no sentido dessa nova materialidade, afirma que “[...] o digital produz um novo tipo 
de relação entre o sujeito e o social, uma nova relação de práticas políticas e discursivas que não são da ordem da banalidade”. Desse modo, faz-se necessário pensar essas novas relações enunciativas, a partir da teoria adotada neste estudo, a Enunciação.

Assim, na primeira seção deste texto, discorremos acerca do comentário de Facebook como nova materialidade enunciativa, uma vez que se dá em um novo espaço de enunciação. Na segunda seção, apresentamos a Reescrituração como teoria e ferramenta analítica que permeia nosso estudo, que se fundamenta em compreender os sentidos a partir do processo da reescritura dos enunciados. Na terceira seção, realizamos o movimento analítico das Sequências Enunciativas que constituem o corpus, por meio do aporte teórico-metodológico mobilizado. Por fim, apresentamos as considerações finais com reflexões que a análise possibilitou suscitar.

\section{COMENTÁRIO DE FACEBOOK: UMA NOVA MATERIALIDADE ENUNCIATIVA}

Nosso objeto de estudo constitui-se de dizeres do senso comum sobre a língua, em uma página no Facebook, a fanpage oficial do Palácio do Planalto, mais especificamente, no vídeo de transmissão ao vivo do primeiro pronunciamento oficial de Michel Temer na condição de presidente, em 2 de setembro de 2016. É imprescindível, portanto, que pensemos o comentário como materialidade enunciativa virtual. Com o advento dos suportes comunicacionais e da mídia digital, houve simultaneamente uma diversificação na produção de escrita e de leitura, que perpassaram um processo de intensa mudança, tanto no âmbito formal como de interações, de atitudes e de intenções.

Deparamo-nos com um formato de escritas sucintas, rápidas, e de um ágil compartilhamento de ideias, em número cada vez maior, superando o processo realizado pelos suportes comunicacionais tradicionais, como rádio, jornal e televisão. Nesse sentido, os textos, flexíveis e adaptáveis aos suportes e às formas de escrita, moldam-se conforme os contextos tecnológicos em que se apresentam para os leitores e os produtores dessas novas realidades de escrita, que se dão principalmente na Internet. Surge, assim, outro espaço de enunciação em que circulam esses dizeres sobre a língua. É um espaço de língua falada e escrita em que circula a língua escrita com fortes marcas da oralidade, produzindo sentidos, em temporalidades e perspectivas distintas das que se vinha pensando.

Para fins de melhor compreender a rede social que dá origem ao nosso corpus, é válido uma breve contextualização. O Facebook foi criado em 2004, nos Estados Unidos, e possui diversas funcionalidades que abrangem diferentes práticas sociais, dentre as quais temos a formação de grupos com interesses específicos, marcação, atualização de status, transmissões ao vivo, comentários sobre postagens, convite e confirmação para eventos, as opções curtir e compartilhar conteúdo. Quanto aos comentários, Barton e Lee (2015, p. 59) afirmam que, “[...] por vezes, [o recurso de comentário] age como um site para mini fóruns de discussão”.

Em um estudo realizado por Bertucci e Nunes (2017), afirma-se a importância do comentário, com a tese de que este é o grau mais profundo de interação entre autor, texto e leitor, em uma rede social como o Facebook, em termos de texto escrito. 
O comentário é o grau mais importante de envolvimento de um usuário, porque exige, além de uma navegação e leitura atentas, disposição e capacidade de contribuir para a ampliação da publicação. É um outro texto, que revela o percurso construído pelo leitor e que soma outros sentidos ao primeiro. (BERTUCCI; NUNES, 2017, p. 323).

O Facebook apresenta uma possibilidade diversa de comentários, podendo ser eles: longos e complexos, curtos, de aprovação ou reprovação sobre alguma temática em discussão, imagem ou informação pessoal, de posicionamento sobre temas como política, religião e esporte. Assim sendo, qualquer assunto de interesse social, positivo ou negativo, é capaz de desencadear uma série de comentários na rede social. E, desse modo, imprevisíveis, oscilam sempre entre um simples e breve enunciado às longas e fervorosas discussões.

Por meio dos comentários, a língua e os dizeres sobre a língua circulam em um novo espaço enunciativo, e, nisso, atravessa o funcionamento político e da historicidade que constituem o sujeito, pois, conforme Dias (2018):

A língua material é a língua em sua historicidade, naquilo que toca a história do sujeito, a história da sociedade em que vive e a história da própria língua. Em outros termos, significa considerar que a relação do sujeito com qualquer língua é atravessada pela história do sujeito e pela história da língua. (DIAS, 2018, p. 171).

Os comentários, como enunciados no espaço de enunciação virtual, tocam a história da língua e do sujeito, uma vez que as relações e os funcionamentos se transformam, sentidos circulam e resultam em novas significações. A natureza inerente à enunciação mantém-se, e transforma-se a materialidade enunciativa.

\section{O FUNCIONAMENTO DA REESCRITURAÇÃO}

Como o intuito desta pesquisa foi estudar o imaginário na perspectiva de como o senso comum enuncia sobre a língua e compreender os processos de constituição de sentidos que compõem esse imaginário, consideramos ser adequado operarmos com reescrituração como movimento de redizer a palavra, um dos procedimentos analíticos da Semântica do Acontecimento. Assim, foi possível recuperar os sentidos atribuídos à variante de português falada por Michel Temer e enunciados pelos sujeitos internautas.

Partindo da afirmação de Guimarães (2002a, p. 7), de que “[...] não há como considerar que uma forma funciona em um enunciado, sem considerar que ela funciona num texto, e em que medida ela é constitutiva do sentido do texto", estamos dizendo que, se algo funciona no enunciado, deve funcionar também no texto, e, portanto, o texto é compreendido como acontecimento enunciativo. Desse modo, uma mesma palavra pode significar coisas diferentes conforme o seu funcionamento no texto possibilita o movimento de sentidos, que pode dar-se pelo processo de reescrituração.

A análise por reescrituração permite-nos compreender que sentido a palavra tem no acontecimento da enunciação. Com isso, mobilizamos as duas designações de maior recorrência nos enunciados "Português Correto" e "Presidente Alfabetizado", definimo-las como os dois 
grandes eixos de sentido e analisamos como essas designações se reescrevem produzindo novos sentidos. A designação consiste no sentido material de uma expressão ou palavra, e não na palavra ou expressão propriamente dita; assim, "português correto" e "presidente alfabetizado" são determinações semânticas que constituem a designação de língua.

Para Guimarães (2002a), a reescrituração é um processo de deriva de sentidos da textualidade. $\mathrm{O}$ autor destaca que não há texto em que não haja esse movimento de deriva de sentidos, o que equivale dizer que a reescrituração é inerente a toda materialidade textual. Assim, é imprescindível compreender como um nome se relaciona com outros nomes por meio da textualidade, “[...] funcionando sob a aparência da substituibilidade” (GUIMARÃES, 2002b, p. 27). O pesquisador define a reescrituração como o procedimento de análise que consiste em identificar o processo de redizer aquilo que já foi dito, e atenta para a delimitação do conceito de textualidade.

Procedimentos como anáfora, catáfora, repetição, substituição, elipse, etc, são procedimentos de deriva do sentido próprios da textualidade. O que pretendo dizer é que as questões tomadas como procedimentos de textualidade são procedimentos de reescritura. Ou seja, são procedimentos pelos quais a enunciação de um texto rediz insistentemente o que já foi dito. Assim a textualidade e o sentido das expressões se constituem pelo texto por esta reescrituracão infinita da linguagem que se dá como finita pelo acontecimento (e sua temporalidade) em que se enuncia. (GUIMARÃES, 2002b, p. 28).

Dessa forma, a textualidade pode ser descrita como aquela que atribui a um conjunto de enunciados a condição de texto e constitui-se como resultado instantâneo de deriva de sentidos. Essa deriva dá-se pela semelhança, igualdade ou recorrência das palavras no texto. Guimarães (2002b, p. 28) afirma que "[...] o procedimento de reescritura no texto faz com que algo do texto seja interpretado como diferente de si. E analisar a designação de uma palavra é ver como sua presença no texto constitui predicações por sobre a segmentalidade do texto, e que produzem o sentido da designação". Com isso, os sentidos são produzidos pela constituição de discursos, do senso comum, sobre o português falado pelo presidente Michel Temer.

Uma das possibilidades de movimento analítico por reescrituração é pelo mecanismo semântico da sinonímia, ou seja, que dizem o mesmo de outro modo por meio de sinônimos; e a irrepetibilidade constitui-se pela sua inscrição em tempo e espaços distintos, que é, em síntese, o sentido da enunciação. No caso do nosso corpus, a irrepetibilidade ocorre pelos fatores citados, porque não é o mesmo sujeito a enunciar, e, com isso, temos o atravessamento de uma condição histórica. Dito de outro modo, a reescrituração é um movimento analítico de localização dentro de um texto, de palavras que dizem o mesmo, mas de outra maneira, ou seja, é repetir no texto. Assim, nosso procedimento analítico constitui-se pela localização das formas nominais que se reescrevem diversas vezes nos enunciados dos sujeitos que compõem o corpus.

Com isso, percebemos que a reescrituração é um procedimento analítico textual de funcionamento semântico e funcionamento linguístico em que a língua se reescreve, e o que ela significa pode ser compreendido a partir do estudo da forma e do sentido que constituem a enunciação. Para tanto, não nos detemos à categorização gramatical propriamente dita, mas a compreender os sentidos dessas reescrituras. 
Para Guimarães (2002a, p. 28), é o texto que constitui o sentido e a textualidade das expressões, pela “[...] reescritura infinita da linguagem que se dá como finita pelo acontecimento (e sua temporalidade) em que se enuncia”. Assim:

A reescrituração é a pontuação constante de uma duração temporal daquilo que ocorre. E ao reescriturar, ao fazer interpretar algo como diferente de si, este procedimento atribui (predica) algo ao reescriturado. E o que ele atribui? Aquilo que a própria reescrituracão recorta como passado, como memorável. (GUIMARÃES, 2005, p. 28).

Em síntese, conforme exposto, o movimento analítico de reescrituração no texto possibilita que uma expressão ou enunciado seja interpretado de acordo com o seu funcionamento semântico. Após a delimitação do nosso corpus e de uma observação minuciosa sobre as recorrências de expressões nas sequências enunciativas, optamos por adotar a reescrituração em nosso processo de análise e compreensão dos sentidos, a partir das Sequências Enunciativas selecionadas.

\section{OS SENTIDOS DE LÍNGUA PELA REESCRITURAÇÃO}

Os movimentos metodológicos constituíram-se, inicialmente, pela seleção de todos os comentários dos sujeitos internautas que faziam referência ao português falado pelo ex-presidente Michel Temer. Após, realizamos um recorte das Sequências Enunciativas (SEs) a serem analisadas de acordo com o método de sondagem proposto por Guimarães (2018), em que o recorte é feito a partir de uma pergunta - a nossa consistia em analisar as distintas ocorrências de reescriturações, selecionando-as conforme a maior recorrência. Assim, neste artigo, analisamos quatro Sequências Enunciativas.

- SE1: "Ele fala o nosso idioma da forma como deve ser falado. Fazia tempo que não ouvia. Força Temer. Vamos vencer”.

A Sequência Enunciativa 1 tem a reescrituração na forma de substituição, e a relação de sentido produzida pela reescrituração por especificação. A forma nominal Português correto aqui é substituída por “nosso idioma”, e traz a especificação “da forma como deve ser falado”. Podemos parafrasear dizendo: há um idioma, que é nosso, ou seja, uma língua comum a todos; há uma maneira correta de se falar essa língua, que é o modo que o presidente a fala, diferente de como os presidentes anteriores falavam.

A especificação remete ao aspecto normativo da língua. Ao determinar “da forma como deve ser falado" o português, faz um recorte justo referindo-se que nem todos fazem uso dessa mesma forma. Pois, se o presidente fala como se deve falar, há os que falam como não se deve falar. Habita também o imaginário do país de uma língua só, ao afirmar “nosso idioma”, apagando, assim, toda a diversidade de "idiomas” que circulam, a língua nacional é homogênea.

Scherre (2005) apresenta, em seus estudos, uma das razões que alimentam a crença na correção, descrevendo-a como a ideia de que fala e escrita são, ou deveriam ser, iguais. Nesse sentido, a autora afirma que: "Não se pode confundir fala com escrita, seja no plano das unidades gramaticais seja no plano do desempenho linguístico. Unidades gramaticais da fala não são necessariamente as mesmas que as unidades gramaticais da escrita. Falar é diferente de escrever” (SCHERRE, 2005, p. 100). 
A compreensão de que a fala difere da escrita é apenas a ponta do iceberg no que se refere ao imaginário de língua, pois há ideologias sustentadas por diferentes âmbitos, conforme explica Moita Lopes (2013). O autor ressalta que “[...] as ideologias linguísticas são múltiplas e advêm de perspectivas políticas, culturais e econômicas específicas” (MOITA LOPES, 2013). Assim, como já especificado anteriormente, as crenças puristas que valoram negativamente as variedades de uma língua são também exemplos de ideologias linguísticas.

O imaginário de língua e as ideologias fundamentam-se em um padrão, como mostra a SE1, em "nosso idioma da forma como deve ser falado", considerando o padrão como modelo de referência para o uso da língua, e tomado como o único correto. No entanto, na prática, o padrão nunca alcançará o seu triunfo, pois, de acordo com Faraco (2016):

O padrão não conseguirá jamais suplantar integralmente a diversidade porque, para isso, seria preciso alcançar o impossível (e, obviamente, o indesejável): homogeneizar a sociedade e a cultura e estancar o movimento e a história. Mesmo assim, o padrão terá sempre, por coações sociais, certo efeito unificador das demais normas. (FARACO, 2016, p. 214).

O imaginário de que há uma forma correta apenas de falar a língua portuguesa toca inúmeros sentidos que significam na história. Assim, silenciosamente apaga o movimento, a vivacidade, a natureza mutável, todas as características inerentes a uma língua em uso na sociedade. Também é possível questionar se o nosso idioma é novamente falado da forma como deve ser falado: Quem representa esse “nós” hoje, além da figura presidencial? Seria a classe altamente letrada, detentora do poder social simbolizado no status? Uma vez que a língua do povo, em sua maioria, não é a língua do presidente, no sentido que é adotado na Sequência Enunciativa 1.

- SE2: "Parabéns Presidente, fala um português perfeito, com classe, Ow alívio, vamos trabalhar agora”.

Nessa SE, a reescrituração dá-se por repetição e sinonímia, uma vez que o sentido de português correto se repete por "português perfeito, com classe". Essa repetição funciona pela sinonímia, tendo o perfeito e com classe como sinônimos de correto. Em outras palavras, o português que é correto é perfeito e tem classe, significando elegância e educação; logo, quem não fala esse português, como o presidente, fala de modo "imperfeito" e "sem classe".

A língua falada nos padrões que se espera no imaginário do senso comum é adjetivada por perfeição e classe. A perfeição é compreendida como o estado máximo de excelência das coisas, pois, quando algo está perfeito, então não há mais o que ser moldado ou modificado. A classe qualifica a perfeição, pois não basta o português de Temer ser perfeito, ainda é falado com classe, e, por isso, recebe os parabéns.

Pinto (2013) retrata a língua falada pelo povo e a língua falada pela parcela altamente instruída da população. A autora destaca alguns aspectos que diferem ambas:

Os iletrados e populares falariam uma variedade ou dialeto iletrado e popular de uma mesma língua, ao contrário dos cultos, que falariam um dialeto ou variedade que segue as regras da língua escrita e da gramática tradicional dessa língua. [...]. Espera-se igualmente que esse grupo culto evite vocábulos e expressões populares e gírias. (PINTO, 2013, p. 127). 
Dessa forma, o português perfeito e com classe, falado pelo presidente, é aquele português categorizado como o correto, que se aproxima da gramática tradicional, e distancia-se do português “popular”, longe da perfeição e da classe. Novamente, há um padrão que produz sentido, adjetivando e qualificando a língua portuguesa, no viés da estética.

- SE3: "Finalmente, após 13 anos de assassinato ao nosso português, temos um presidente da república que sabe utilizar verbos, adjetivos, pronomes, substantivo, artigos... Podemos nos orgulhar apenas por isto. Lembro na época da Anta, quando eu ficava com vergonha em ser brasileiro”.

O modo de reescrituração da Sequência Enunciativa 3 é por condensação, e o sentido por enumeração. "Finalmente após 13 anos de assassinato ao nosso português” condensa todo período histórico que antecedeu a atual presidência, por meio do advérbio "finalmente”. O sentido dá-se por enumeração uma vez que qualifica o presidente da república como aquele "que sabe utilizar verbos, adjetivos, pronomes, substantivo, artigos...”, e isso é um motivo de orgulho.

Os sentidos políticos que se movimentam no interior do enunciado remetem ao imaginário de língua que estamos observando ao longo de toda a análise. Aqui, o presidente da república não assassina o português porque sabe utilizar verbos, adjetivos, pronomes, substantivos e artigos; dessa maneira, possui conhecimento gramatical que reflete em sua fala, consolidando-a como um modelo a ser seguido, já que é razão de orgulho.

A segunda parte da SE3 refere-se a um dos governos anteriores, citado como "época da Anta” que provocava "vergonha em ser brasileiro”, em decorrência dos usos linguísticos desse presidente, que não se aproximariam tanto da norma padrão como Michel Temer. Dessa forma, o uso oral da língua portuguesa pelos sujeitos transita entre o orgulho e a vergonha, conforme se aproxima ou se distancia do modelo gramatical.

Scherre (2005) explica o estigma social que circunda os sujeitos que falam a língua portuguesa sem atentar-se às concordâncias devidas, conforme prega a gramática, e isso acaba resultando em uma segregação entre aqueles “que sabem falar” e os que “não sabem falar” português.

A falta de concordância verbal (nós vai) ou nominal (dois pastel), esta, sim, é denominada erro, e a pessoa que não faz concordância, além de carregar um forte estigma de não saber falar português, de ser um brasileiro que tem dificuldade de se expressar corretamente, pode não só perder o emprego, mas até, dizem (ou diziam), a eleição para a Presidência da República. Isso acontece não porque a falta de concordância acarreta problemas na comunicação, mas porque ela distingue grupos sociais: tendem a fazer mais concordância pessoal de classes com mais prestígio social ; tendem a fazer menos concordância pessoas de comunidades com menos prestígio social, embora todos os brasileiros, em maior ou menor grau, deixem de fazer concordâncias no uso espontâneo da linguagem. (SCHERRE, 2005, p. 123).

O imaginário está nisto: o bom uso gera orgulho, inclusive alheio, pois observamos os locutores dos enunciados expressando esse sentimento em relação ao português do presidente Michel Temer. A língua que é praticada cotidianamente pelos longínquos recantos dessa nação, e que não atenta para as normas da gramática, é uma “língua assassinada”, razão de vergonha. 
- SE4: "Graças a Deus! Um presidente alfabetizado, que se articula nas palavras com grande maestria. Parabéns, que o Brasil vença, com a fé, esperança e trabalho”.

A Sequência Enunciativa 4 apresenta o seu modo de reescrituração por repetição, e o sentido por especificação, pois "um presidente alfabetizado" é especificado como aquele que "se articula nas palavras com grande maestria". A forma nominal "presidente alfabetizado" reescriturada por repetição adquire sentido por meio da especificação.

Relaciona-se uma boa capacidade oratória à alfabetização, como se uma fosse consequência da outra. O presidente articula-se nas palavras com grande maestria porque é alfabetizado, e vice-versa. O imaginário presente nessa SE é o mesmo que já percebemos anteriormente, e que se constitui, principalmente, a partir da ausência de distinção entre língua falada e escrita, e do conhecimento de que uma língua jamais será homogênea, em decorrência de uma série de fatores sócio-históricos imbricados.

Leite (2008), em sua obra Preconceito e intolerância na linguagem, discute sobre os modos como o preconceito e a intolerância linguística estão camuflados nos discursos e atingem o cerne das individualidades, uma vez que a linguagem é o que o homem tem de mais íntimo e, por isso, é o que representa a sua subjetividade.

Tratar a língua em uso implica saber interpretá-la sob diversos enfoques, dentre os quais o discursivo, o textual e o gramatical. Isso é muito diferente de entender que a língua se restringe a um punhado de regras da gramática tradicional e que elas são a norma culta! E é essa a batalha, contra o preconceito e a intolerância linguísticos, que se tem de travar para que não se afirme por aí que "A dificuldade com a clareza é um traço cultural do Brasil”. (LEITE, 2008, p. 103).

Assim, compreendemos que se "articular nas palavras com grande maestria” não é uma característica necessariamente decorrente do grau de instrução do sujeito, apesar de serem assim assimilados no senso comum. Na SE em questão, os sentidos movem-se com mais intensidade em relação à boa oratória de Michel Temer, detalhe que chamou atenção dos sujeitos internautas imediatamente após a sua posse, e levou a associação ao seu alto nível de instrução.

Tem-se criado um ideal de língua, que, como já referido, é a língua da gramática, e todas as variedades que se distanciam dela não recebem o mesmo prestígio social. Contudo, o que se ignora no imaginário do senso comum é o fato de que a língua é um todo, independentemente do seu nível empregado na modalidade oral (culto, padrão ou coloquial), e, em decorrência disso, está em sua totalidade suscetível às mudanças condicionadas pelo tempo e pela história. Conforme explica Leite (2008):

A norma culta é, como todas as normas, dinâmica, mutável. Até mesmo autores de gramáticas tradicionais de grande credibilidade reconhecem essa mobilidade da norma e incorporam no bojo do texto de suas gramáticas alguns usos que, em outras épocas, eram considerados inapropriados ao domínio culto. (LEITE, 2008, p. 102).

Dessa forma, uma fala "engessada”, presa à tradição gramatical, não condiz com a realidade, pois, por mais que o sujeito "se articule nas palavras com maestria”, não significa que não possua nenhum “tropeço” à luz das normas. A gramática é sólida, fixa; a língua é viva. 
O movimento de sentidos revelou o imaginário de que há uma forma correta de falar e que esta deve ser usada para que se possa legitimar o lugar que o sujeito ocupa na sociedade. Ao encontro desse argumento, Dias (2018, p. 182) afirma que "[...] a boa postura, a boa forma, e boa língua é marca representativa do ‘sujeito letrado’, do ‘bom português', da autoridade respeitável”. Desse modo, observamos que, a partir dos sentidos reescriturados, a "língua correta” falada pelo ex-presidente Michel Temer o qualifica para o seu posto antes da sua competência política, pois, no imaginário discursivisado pelo senso comum, falar um "bom português" é sinônimo de um alto grau de escolarização, de letramento, de conhecimento normativo da língua, e, portanto, motivo de orgulho para quem é representado por um sujeito dotado dessa qualidade.

Há um imaginário de que todo sujeito escolarizado fará, por consequência, uso de uma língua padrão-culta, e que não cometerá erros de português em seus discursos. Isso ocorre em decorrência de a escola, na maioria das vezes, ignorar a existência das variedades da língua e não ensinar sobre a heterogeneidade linguística. É evidente que cabe à escola o papel de ensinar a língua padrão; no entanto, o erro está no fato de apenas se deter nessa norma, deixando de lado todas as outras, tão presentes na rotina da população. Bagno (2003, p. 27) traz essa situação ao afirmar que: “A escola tenta impor sua norma linguística como se ela fosse, de fato, a língua comum a todos os quase 190 milhões de brasileiros, independente[mente] de sua idade, de sua origem geográfica, se sua situação socioeconômica, de seu grau de escolarização etc.”.

É possível observar claramente que o discurso do senso comum é permeado por um imaginário de língua fortemente marcado. Esse imaginário edifica-se sobre uma ideologia fundante, que toma a língua como instrumento simbólico de poder, capaz de colocar sujeitos em espaços inalcançáveis pelos demais, pelo simples fato de terem o domínio da norma, do bem falar. Além disso, esse imaginário revela um pensamento em defesa do purismo linguístico, como se a língua fosse homogênea e as variações no uso, inadmissíveis, conforme explica Faraco (2016):

Embora a defesa purista não tenha nenhum resultado prático - no sentido de difundir a norma padrão, 'higienizando' (como desejariam seus paladinos) a norma culta brasileira -, ela tem efeitos negativos sobre o modo como tradicionalmente se representa a língua no imaginário do Brasil, vista aí, com frequência, como cheia de erros e deformações. O país tem tido, ao longo de século e meio, grandes dificuldades para reconhecer seu rosto linguístico e, em consequência, para promover uma educação linguística consistente. (FARACO, 2016, p. 363).

As tantas ideias sem fundamentação científica difundidas no senso comum têm as suas raízes fixadas em âmbitos e ideologias específicas, e causam dissenso na sociedade quando o assunto é língua. Scherre (2005), a partir de uma ampla análise de conteúdos divulgados na mídia sobre questões linguísticas, refere-se à questão afirmando que

[...] a mídia brasileira vem prestando um real desserviço à inteligência e à dignidade humana, ao estabelecer identidade entre gramática normativa e língua ou idioma de um povo; ao reforçar a confusão entre língua falada e língua escrita; ao instigar e fortalecer o preconceito linguístico. Mais do que isto, a mídia brasileira tem faltado com a verdade, ao enfatizar a ideia de que as formas linguísticas de 
prestígio são as únicas formas certas do ponto de vista da estrutura linguística. (SCHERRE, 2005, p. 116).

Para Bauman e Briggs (2003, p. 17): "Modos de falar e escrever fazem com que as classes sociais, o gênero, as raças e as nações pareçam reais e os tornem capazes de justificar relações de poder, possibilitando que os subalternos pareçam falar de modos que clamem pela subordinação deles próprios”.

\section{CONSIDERAÇÕES FINAIS}

Por meio do procedimento analítico da reescrituração, pudemos observar, neste texto, o movimento de sentidos que ocorre nos enunciados em relação ao português falado pelo ex-presidente Michel Temer. As reescriturações remetem ao pensamento de que, para ocupar a cadeira presidencial, o sujeito necessita ser altamente letrado e conhecedor das normas da língua. O bom uso da língua portuguesa funciona como denominador comum para qualificar o sujeito ao seu posto de presidente, ou seja, ao lugar de poder, de visibilidade e de representação do povo. Nessa perspectiva, Dias (2018, p. 179) afirma que, “[...] no Brasil, a qualidade de um político passa pela capacidade de domínio da língua normativa”, o que se confirma nos enunciados.

Os sentidos giram em torno de uma divisão social, e, nisso, há um funcionamento político. A capacidade de fazer uso de um "português correto” segrega os sujeitos a duas margens totalmente distintas, que não dialogam, pois o lugar da "boa língua” sobrepõe-se imensuravelmente à língua coloquial do povo, à língua fluida, em funcionamento no cotidiano. Assim, solidifica-se um espaço de divisão política entre aqueles que falam bem e os que não falam. Essa divisão é parte de um imaginário de língua e, também, alimenta um preconceito linguístico que, por vezes, é inclusive instigado pela mídia.

Ao considerarmos os equívocos da mídia no que diz respeito à língua portuguesa e de como, na condição de um aparelho ideológico, contribui na disseminação de ideias impertinentes que geram imaginários sem sustentação alguma, que servem apenas para agregar mais preconceito e intolerância às variedades da língua, surge outro cenário midiático que é imprescindível que pensemos: a Internet. É desse meio, hoje em seu auge de utilização no âmbito global, que obtivemos o nosso corpus, e é nesse meio que se faz necessário pensar a língua portuguesa também, pois, conforme Oliveira (2013, p. 55): "Na internet, o português alcançou recentemente a cifra de 87 milhões de usuários, passando a ser, em 2010, a quinta língua mais usada na rede - à frente do japonês”. Assim, os equívocos oriundos da mídia tradicional, ainda considerada a voz da verdade, alojam-se no imaginário do senso comum e, depois, seguem para a sua disseminação no meio virtual, por meio da Internet.

A análise semântica, a partir dos pressupostos da teoria da Enunciação, na perspectiva da Semântica do Acontecimento, evidencia que o domínio oral da língua portuguesa pelo sujeito chama atenção, seja pelo seu "bom português”, ou “assassinato da língua portuguesa” - nos mesmos sintagmas recorrentes. Trata-se de algo além de uma simples distinção de uso linguístico. Trata-se de poder, de ideologia, de dominação e de subordinação. 


\section{REFERÊNCIAS}

BAGNO, M. A norma oculta. Língua \& poder na sociedade brasileira. 2. ed. São Paulo: Parábola Editorial, 2003.

BARTON, D.; LEE, C. Linguagem online: textos e práticas digitais. São Paulo: Parábola Editorial, 2015.

BAUMAN, R.; BRIGGS, C. Language ideologies and the politics of inequality. Voices of Modernity. Cambridge: Cambridge University Press, 2003.

BERTUCCI, R. A.; NUNES, P. Á. Interação em rede social: das reações às características do gênero comentário. Domínios de Lingu@gem, Uberlândia, v. 11, n. 2, abr./jun. 2017. https:// doi.org/10.14393/DL29-v11n2a2017-3

CARPENEDO, R. F. A reescrituração e os sentidos de língua na perspectiva do senso comum: ideologia e imaginário. 2017. Dissertação (Mestrado em Letras/Estudos Linguísticos) - Universidade Federal de Santa Maria, Santa Maria, 2017.

DIAS, C. Análise do discurso digital: sujeito, espaço, memória e arquivo. Campinas: Pontes Editores, 2018.

FARACO, C. A. História sociopolítica da língua portuguesa. São Paulo: Parábola Editorial, 2016.

GUIMARÃES, E. Os limites do sentido. Campinas: Pontes, 2002a.

GUIMARÃES, E. Semântica do Acontecimento. Campinas: Pontes, 2002b.

GUIMARÃES, E. A língua portuguesa no Brasil. Ciência e Cultura, São Paulo, v. 57, n. 2, abr./jun., p. 24-28, 2005

GUIMARÃES, E. Semântica: enunciação e sentido. Campinas: Pontes Editores, 2018.

LEITE, M. Q. Preconceito e intolerância na linguagem. São Paulo: Contexto, 2008.

MOITA LOPES, L. P. da. (org.). O Português no século XXI: cenário geopolítico e sociolinguístico. São Paulo: Parábola Editorial, 2013.

OLIVEIRA, G. M. de. Um Atlântico ampliado: o português nas políticas linguísticas do século XXI. In: MOITA LOPES, L. P. da. (org.). O Português no Século XXI: cenário geopolítico e sociolinguístico. São Paulo: Parábola Editorial, 2013. p. 53-73.

PINTO, J. P. Prefiguração identitária e hierarquias linguísticas na invenção do português. In: MOITA LOPES, L. P. da. (org.). O Português no século XXI: cenário geopolítico e sociolinguístico. São Paulo: Parábola Editorial, 2013. p. 120-143.

SCHERRE, M. M. P. Doa-se lindos filhotes de poodle: variação linguística, mídia e preconceito. São Paulo: Parábola, 2005.

Recebido em: jun. 2020.

Aceito em: set. 2020. 